\title{
Mobility, habitat selection and population connectivity of the butterfly Lycaena helle in central Sweden
}

\author{
Hanna Modin ${ }^{1} \cdot$ Erik Öckinger ${ }^{1} \mathbb{D}$ \\ Received: 9 January 2020 / Accepted: 13 July 2020 / Published online: 18 July 2020 \\ (c) The Author(s) 2020
}

\begin{abstract}
To be able to predict habitat quality and potential distribution of threatened species is key to developing successful conservation strategies for threatened species with fragmented distributions. The aim of this study was to assess factors that limit the local distribution and density of Lycaena helle, an endangered butterfly, in central Sweden, and to estimate its mobility in order to classify local populations according to their importance for the connectivity on a regional level. An additional aim was to test if $L$. helle habitat quality could be assessed using remotely-sensed data such as laser scanning (LiDAR). We derived potential predictors of $L$. helle occurrence from laser scanning data and used a resource selection function to assess their predictive power. We used a mark-recapture approach to study $L$. helle movement and estimate dispersal distances. The probability of occurrence of $L$. helle increased with higher solar irradiation and was negatively affected by sloping terrain, but the LiDAR data generally had low predictive power. Population density increased with host plant density, but this effect was weak. The mark-recapture study confirmed that $L$. helle is very sedentary, with a mean movement distance of only $114 \mathrm{~m}$ and a maximum of $600 \mathrm{~m}$. The studied population extends over a large network of interconnected linear habitats, which probably facilitates dispersal and thereby population persistence. Our study highlight the importance of a warm micro-climate and of man-made habitats like road verges and power-line corridors for the conservation of $L$. helle.
\end{abstract}

Keywords Dispersal $\cdot$ Lepidoptera $\cdot$ Mark-recapture $\cdot$ Metapopulation $\cdot$ Resource selection function $\cdot$ Stepping stone

\section{Introduction}

Loss of biodiversity is a worldwide concern that is driven mainly by habitat degradation and fragmentation (Pimm et al. 2014; Saunders et al. 1991). Many specialized butterflies are strongly negatively affected by habitat loss and fragmentation (Öckinger et al. 2010), making them a useful model group for studies on the effects of habitat loss and fragmentation on species persistence (Thomas 2005). For species with fragmented distributions, knowledge about the determinants behind patch occupancy and local population densities is key to developing successful conservation

Electronic supplementary material The online version of this article (https://doi.org/10.1007/s10841-020-00254-y) contains supplementary material, which is available to authorized users.

Erik Öckinger

erik.ockinger@slu.se

1 Department of Ecology, Swedish University of Agricultural Sciences, Box 7044, 75007 Uppsala, Sweden strategies (Dennis et al. 2003; Fourcade and Öckinger 2017). Both local habitat area and quality and landscape context such as connectivity to other populations can influence patch occupancy and local population densities (Fleishman et al. 2002; Thomas et al. 2001). Habitat loss and fragmentation leads to the disruption of colonization-extinction dynamics in metapopulations, resulting in an increased risk of regional extinction (Hanski 1998). To maintain functioning metapopulations, it is crucial to identify populations and habitat patches (i.e. stepping stones) that are important from a connectivity perspective and to which conservation efforts should be directed (Heller and Zavaleta 2009; Saura et al. 2014). Connectivity models based on network analysis (graph theory) are a useful tool to identify such stepping stones (Saura and Rubio 2010).

On the local scale, factors such as resource abundance and vegetation structure can be important (Fleishman et al. 2002; Thomas et al. 2001). The abundance of essential resources limit the carrying capacity of local populations. Vegetation structure in combination with topography are important determinants of micro-climate, which is a key 
component of habitat quality for many ectothermic animals, such as insects (Bonebrake et al. 2010; Eilers et al. 2013). Resource selection functions (RSFs) can be used to investigate which factors best predict a species' spatial use of a habitat (Boyce et al. 2002).

The Violet Copper butterfly Lycaena helle is listed as 'endangered' on the European Red List of butterflies (van Swaay et al. 2010), and also on the national Swedish Red List (Artdatabanken 2015). Fennoscandian populations of $L$. helle have been described as a separate subspecies, L. helle lapponica, and differ from populations in Central Europe in e.g. host plant use (Ryrholm 2014). Studies from Central Europe show that micro-climatic conditions are an important aspect of the habitat of L. helle, and that L. helle is favoured by high solar radiation and low vegetation (Skórka et al. 2007), but also a variable vegetation cover that provides wind shelter (Sawchik et al. 2003). In Central Europe, L. helle is extremely sedentary and a poor colonizer (Craioveanu et al. 2014; Fischer et al. 1999; Turlure et al. 2014). As a consequence, it is highly sensitive to habitat fragmentation and isolation of populations (Sawchik et al. 2003). However, given the differences in ecology between Central European and Fennoscandian forms of $L$. helle, it is unclear how informative these findings are for the conservation of L. helle in Northern Europe.

In Sweden, the distribution of L. helle has decreased significantly since the mid-1900s (Ryrholm 2014), and the population size decreased with 20-45\% during 2005-2015 (Eliasson 2012). The current population size in Sweden is estimated to between 3500 and 10,500 reproductive individuals, distributed over ca. 70 populations (Lindeborg 2014 and Fig. 1). The observed decrease in Sweden has been attributed mainly to habitat degradation and fragmentation as a consequence of altered agricultural practices, especially abandonment of traditionally managed grasslands and intensified management of remaining grasslands (Eliasson 2012; Ryrholm 2014). Loss and fragmentation of habitats, leading to increasing isolation between remnant populations and subsequent collapse of metapopulation dynamics (Hanski 1999) has been suggested as a possible explanation as to why $L$. helle has disappeared from a number of sites where the habitat still appears favourable (Mutanen and Välimäki 2014). Understanding dispersal distances is key to prioritize areas for habitat management and restoration for threatened species.

This study aimed at increasing the knowledge on the habitat requirements and dispersal ability of $L$. helle in Sweden, and to analyse the connectivity of existing populations. An important question is whether habitat quality is mainly determined by host plant availability or by vegetation structure, which in turn influences micro-climate. First, we hypothesized that the habitat quality of $L$. helle is strongly determined by microclimatic conditions, and tested to what extent remotely-sensed variables relating to solar radiation, vegetation height, variation in vegetation height, slope and aspect can predict presence and absence of $L$. helle. Second, we tested if the population density of $L$. helle is related to the abundance of the larval host plant Bistorta vivipara and to vegetation height, as measured in the field. Here, we hypothesized that the population density of $L$. helle is positively related to the host plant abundance and is highest at an intermediate vegetation height. Third, we

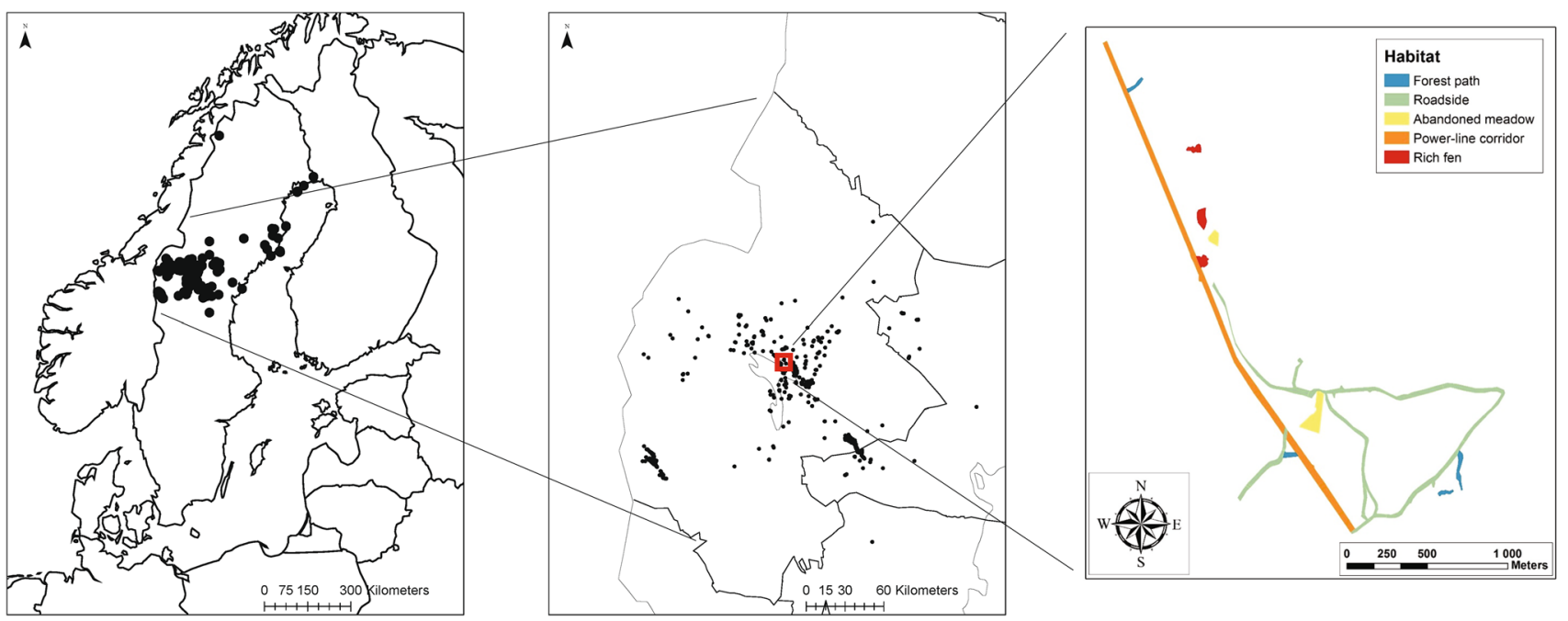

Fig. 1 Left: The distribution of Lycaena helle in Sweden. Data from the Swedish LifeWatch Analysis Portal (Leidenberger et al. 2016), all databases, years 2000-2019. Centre: Jämtland County in central Sweden, the region used for the regional connectivity analyses, with the distribution of L. helle and the study area indicated. Right: The area where the field study was conducted. Background maps: () Lantmäteriet 2018 
used mark-release-recapture data to estimate the dispersal capacity of $L$. helle and performed a regional connectivity analysis to identify the populations in Jämtland County that are most important from a stepping-stone perspective and to which conservation efforts should be directed.

\section{Methods}

Historically, the primary habitats of L. helle in Scandinavia are flower-rich moist grasslands that are maintained by extensive mowing or grazing regimes. With the decrease and fragmentation of traditionally managed grasslands, $L$. helle has become increasingly dependent on naturally open grassland and wetland areas, but also on novel man-made habitats such as roadsides, power-line corridors and military training fields, where the vegetation is kept low (Ryrholm 2014). In areas with high precipitation, L. helle can occur in drier habitats (Eliasson et al. 2005), but in general, good access to moving groundwater is considered important (Eliasson 2012).

\section{Study area}

The field study was conducted in a $2 \times 3 \mathrm{~km}$ area situated about $5 \mathrm{~km}$ from central Östersund, Jämtland County in central Sweden (Fig. 1). The area was selected because observations on Artportalen indicated that it contains an extant metapopulation of L. helle. Part of the study area belongs to the nature reserve Tysjöarna, which has one of the largest calcareous wetlands in the world. Another part of the study area is located within a military training field. We first identified potential L. helle habitat within the study area from aerial photographs, followed by field visits where we searched for presence of the larval host plant $B$. vivipara (Modin 2018). The potential habitat for L. helle within the study area consisted of roadsides $(44.3 \%)$, power-line corridors (39.6\%), abandoned meadows (7.5\%), rich fens (4.5\%) and forest paths $(4.1 \%)$.

\section{Field data}

To estimate the mobility of L. helle and collect data to parameterize the RSF, we performed a mark-releaserecapture study throughout our study area. During 23 days between the 23rd of May and the 7th of July 2017, we walked through the area searching for L. helle (Modin 2018). All encountered individuals were captured, marked with a unique ID and released at the point where they were captured. Recaptures of already marked butterflies were recorded. GPS locations were taken at the points of capture and recapture of each individual butterfly. Depending on the weather conditions, it was sometimes possible to cover the whole area in one day, but if not, the search was resumed the next day with suitable weather conditions. Care was taken to vary the time of day that was spent at the different locations. The search effort was the same in the whole area.

To investigate the relationship between $L$. helle density and the abundance of $B$. vivipara and fine-scaled vegetation height, respectively, we placed 171 quadrats of $1 \times 1 \mathrm{~m}$ throughout the study area. Care was taken to distribute the quadrats relatively evenly both along the width and length of the area but as the study area expanded continuously and some inventories were made at the start of the study, the quadrats were more widely dispersed in some parts than in others. Within each quadrat, we counted the total number of $B$. vivipara and measured the vegetation height at five points. Vegetation height was only measured up to $1 \mathrm{~m}$, to account for more small-scale differences than in the vegetation raster based on the LiDAR data. In the analyses we used the average of these five measurements.

\section{Analyses}

\section{Habitat selection using a resource selection function}

We analysed habitat selection by assessing how remotelysensed variables can predict the local distribution of $L$. helle using a Resource selection function (RSF). RSFs aim to measure non-random relationships between an animal's geographic position and environmental conditions (Morris et al. 2016). This is done by assessing the probability of the species using certain resources compared with the availability of those resources in the environment (Boyce et al. 2002). To compute an RSF, data on the presence locations of the species and of the resource availability across the study area are needed (Manly et al. 2007). RSFs are commonly used within conservation and management (Boyce et al. 2002).

The capture locations from the mark recapture study were used as presence points, but, to avoid autocorrelation, the recapture locations were not used. The absence points were randomly distributed in the parts of the study area where no L. helle had been found, in spite of frequent visits. The number of absence points was set to equal the number of presence points and were distributed at least $5 \mathrm{~m}$ away from each other, outside a fixed radius around the presence locations. The radius was set to equal the median observed movement distance ( $81.9 \mathrm{~m}$; see below). As the aim was to identify the habitat preferences of $L$. helle within seemingly suitable habitat, absence points were only distributed within potential habitat, i.e. roadsides, power-line corridors, abandoned meadows, rich fens and forest paths within the study area.

Five habitat variables that are easily extractable from readily available remotely-sensed data were included in the RSF to assess their relative importance: Vegetation height, Topographic Position Index Slope, Solar radiation and 
Aspect. The Topographic Position Index provides a measure of the heterogeneity of vegetation height, while still taking into account important terrain features such as ditches (Jenness 2006). The aspect was measured in degrees. All of these variables were computed in ArcMap 10.5.1 (ESRI 2017) based on Laser scanning (LiDAR) data, which were downloaded from Lantmäteriet and created by laser scanning from airplanes (Nordkvist and Olsson 2013). Laser scanning provides elevation data with the highest resolution available for this area. The laser beams can separate bedrock/ground from vegetation/buildings, making it possible to transform the LiDAR data to a high-resolution digital elevation map (DEM) and digital surface map (DSM). The DEM covers the elevation at ground level, whereas the DSM covers the elevation at the height of the canopy cover. In the area around Östersund, one measurement per $2 \mathrm{~m}^{2}$ has been made. A detailed description of the procedure to compute these variables based on the LiDAR data is given in the Electronic Supplementary Material and in Modin (2018).

The habitat characteristics were tested for intercorrelations using Spearman's rank-order correlation. Significant correlations were found between solar radiation and TPI, solar radiation and vegetation height, slope and TPI as well as slope and vegetation height. No correlation coefficient (rho) was particularly strong and the maximum deviation from zero was -0.241 (solar radiation and vegetation height). As a result of the low correlation coefficients, all variables were included in the habitat selection analysis in spite of the four significant correlations.

The data was statistically analysed in R 3.4.1 (R Development Core Team 2017) using the package Glmulti (Calcagno and de Mazancourt 2010). Glmulti provides automated model selection and model averaging based on a specified Information Criterion (AIC, AICc or BIC). To correct for the small sample size, AICc was used in this study. Glmulti works as a wrapper for generalized linear models, in this study used with a binomial family and logit link function. The models were selected by a genetic algorithm that can be used when large candidate sets make exhaustive screening unfeasible. Sixty-four models were run in the first screening, which included only main effects and no interactions. In the three subsequent screenings, the best-performing model from the first screening was extracted and one pairwise interaction per screening was appended to the best-performing model. The interactions that were hypothesized to be of interest were slope*northing, slope*easting and vegetation height*TPI. A null model with only intercept was created to compare the other models against.

To evaluate the best model, a receiver operating characteristic (ROC) curve was computed. ROC curves are a dominant tool in evaluating the accuracy of models predicting distributions of species. The true positive rate (sensitivity) was plotted as a function of the false positive rate (100-specificity) at different cut-off points. Each point on the ROC curve represents a sensitivity/specificity pair corresponding to a particular decision threshold. A test with perfect discrimination (no overlap between the two distributions) has a ROC curve that passes through the upper left corner (100\% sensitivity, $100 \%$ specificity). This means that the closer the ROC curve is to the upper left corner, the higher the overall accuracy of the test (Zweig and Campbell 1993). To compensate for possibly "overfitting" the data by running such a large number of models, focus was successively redirected to the model-averaged estimates of the predictors and their overall importance values. The automated model selection is considered part of a multimodel inference approach.

\section{Effects of host plant abundance and vegetation height on $L$. helle density}

The field measures of host plant density and vegetation height were only made in the areas where the butterflies were found and could therefore not be included in the habitat selection analysis. The counts of $B$. vivipara and the average vegetation height were interpolated using the technique IDW (Inverse distance weighted) in ArcMap, with a fixed radius of $100 \mathrm{~m}$, to create a raster with extractable values.

We calculated a density raster of $L$. helle individuals from the capture and recapture locations using the Kernel density tool in ArcMap (Fig. S3). The search radius was set to equal the median flight distance from the mark recapture study and a geodesic distance method was used. For the density raster, both capture and recapture locations were used to include effects such as source-sink dynamics. The values from the two interpolation rasters and from the density raster were then extracted to the presence points, i.e. the captured individuals. The recaptures were not included in this step to avoid autocorrelation. Four presence points had to be removed, as there was no data on B. vivipara or vegetation height at these locations. Pearson's product-moment correlations were run in $\mathrm{R}$ to test how well abundance of $B$. vivipara and vegetation height $<1 \mathrm{~m}$ correlate with $L$. helle density. For vegetation height, we tested both for a negative quadratic correlation and a linear correlation.

\section{Mobility and regional connectivity}

We used the mark-recapture data to estimate dispersal ability. In the data analysis, the shortest distance between capture and recapture points was used. This does not reflect the real flight pattern of the butterflies but it roughly indicates dispersal ability and site fidelity. When individuals were recaptured more than once, only the last recapture was used to avoid autocorrelation. At least one night had to pass between capture and recapture. There was no correlation 
between number of nights between captures and movement distance.

To analyse the regional connectivity of L. helle, all observations of this species from within the Jämtland County were downloaded from Artportalen (www.artpo rtalen.se), a platform where the public, professionals and scientists can upload species observations. Artportalen also contains data from systematic surveys $L$. helle performed as part of the national action programme for this species. We included observations from the past 10 years, i.e. the years 2007-2016. However, for observations in rich fens, which generally constitute a stable habitat over long time, we set the limit to the last 15 years, i.e. the years 2002-2016, after consultation with experienced personnel at the County administrative board of Jämtland. In some locations, several observations had been made from the same population, but with slightly different spatial coordinates. A manual effort was made to delete observations that were within the median flight distance from another observation and that could therefore be considered to belong to the same population. Also observations that were further than the maximum flight distance from all other observations were deleted from the connectivity analysis, as they would not be relevant from a connectivity perspective. The median and maximum flight distances from the mark-recapture study were used. After the selection processes, 156 observations remained and were used in the analysis in this study. In order to not skew the results in favour of the populations within the mark-recapture study area, no observations that were made within the scope of this study have been included.

The connectivity analysis was performed in ArcMap and in the program Conefor 2.6 (Saura and Torné 2012). In Conefor, the recommended probabilistic index called probability of connectivity (PC) was used. PC is a graphbased habitat availability metric that quantifies functional connectivity (Saura and Pascual-Hortal 2007). The index characterises the connections between different populations through a probability of direct dispersal. By using the connection probabilities, the $\mathrm{PC}$ index can rank the populations according to their importance for the overall connectivity. The PC index consists of three separate fractions, which quantify the different ways in which individual landscape elements such as populations or patches can contribute to the overall habitat connectivity in the landscape. Here, we focus on the PC connector fraction of the PC index. This is the contribution of patch $\mathrm{k}$ to the connectivity between other habitat patches, as a connecting element or stepping stone between them. This fraction depends only on the topological position of a patch or link in the landscape network. The populations can get a $\triangle \mathrm{PC}$ connector value $>0$ only if they are part of the best (maximum product probability) path for dispersal between two other patches (Saura and Rubio 2010). A large or small part of the overall connectivity may be lost when a certain population is removed from the landscape, depending on the alternative paths between the remnant populations that are available after the loss. If a large part of the connectivity is lost in case the population disappears, the concerned population gets a high $\triangle \mathrm{PC}$ connector value.

To be able to run the PC index, the likelihood of the different connections had to be calculated. For this purpose, a negative exponential function was fitted to the proportional frequency distribution of flight distances found in the mark recapture study, using automated model selection in the software program Eureqa version 0.98 beta (Schmidt and Lipson 2014). The exponential function was then multiplied with the length of the different connections, yielding the probability for each connection to be used by an individual from any of the connected populations. The maximum distance at which two populations could be considered connected was set to the maximum flight distance found in the mark recapture study. All connections consisted of the shortest straight between the observations. The patch attribute was fixed to 50 for all patches, as no attributes were known for all populations and no influence from varying patch attributes was desired. All PC connector values were joined to their respective populations.

\section{Results}

\section{Mark-recapture}

In total, 229 individuals were marked during the markrecapture study. The total number of encounters was 279 , of which 229 were first-time encounters, 40 final encounters and 10 intermediate encounters. The overall recapture rate was $17.9 \%$, if both final and intermediate encounters are included. The marked individuals were recaptured after 1-26 nights, with a mean of 10 nights and a median of 9 nights passing between first and last encounter.

\section{Habitat selection}

The presence of $L$. helle was unevenly distributed across habitat types (Fig. 2). Whereas the majority of the presence points $(58.1 \%)$ occur in the power-line corridor, only $7.0 \%$ of the random absence points were distributed in this habitat. Instead, the vast majority of absence points (79.0\%) occur along roadsides. The most parsimonious model included a positive effect of solar radiation and negative effects of slope, TPI and vegetation height on L. helle occurrence (Table 1). This model was considerably more likely than the second-best $(\triangle \mathrm{AICc}=1.93$; Table $\mathrm{S} 1)$, and had an area under the ROC curve (AUROC) of 0.685 . Using a model averaging approach yielded very similar patterns, with the strongest support for a positive effect of solar radiation and a 


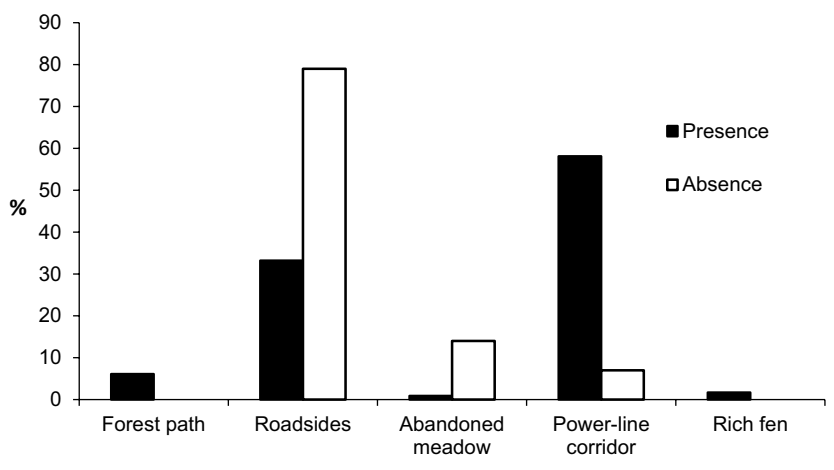

Fig. 2 The distribution of presence and absence points in the different habitats

Table 1 Parameter estimates from the most parsimonious model of habitat selection

\begin{tabular}{lrlrr}
\hline Independent variables & Estimate & Standard error & $\mathrm{z}$ value & $\mathrm{p}$-value \\
\hline (Intercept) & -0.053 & 0.102 & -0.521 & 0.603 \\
Solar radiation & 0.713 & 0.133 & 5.357 & $<0.001$ \\
Slope & -0.297 & 0.105 & -2.827 & 0.005 \\
Topographic Position & -0.252 & 0.105 & -2.366 & 0.018 \\
$\quad$ Index & & & -2.209 & 0.027 \\
Vegetation height & -0.247 & 0.114 & &
\end{tabular}

negative effect of slope, and also relatively strong support for negative effects of TPI and vegetation height (Table 2). The addition of selected pairwise interactions did not improve the best-performing model (Table S1 in Electronic Supplementary Material).

\section{Effects of host plant abundance and vegetation height on L. helle density}

The kernel density raster was based on all 279 encounters with $L$. helle individuals (Fig. S3). There was a statistically

Table 2 The model-averaged predictor statistics, with unconditional estimates, variance and importance of each variable. Northness and Eastness refer to the slope (see Methods) The unconditional estimates are weighted averages of the parameter estimates across all 64 significant but relatively weak positive correlation between the abundance of $B$. vivipara and the kernel density of $L$. helle $(\mathrm{r}=0.233, \mathrm{P}<0.001)$. Similarly, there was a statistically significant but weak negative relationship between vegetation height and L. helle density $(\mathrm{r}=-0.315, \mathrm{P}<0.001)$. The correlation between quadratic vegetation height and $L$. helle density was not statistically significant $(\mathrm{P}=0.53)$.

\section{Mobility and regional connectivity}

The average movement distance for the recaptured individuals was $114 \mathrm{~m}$, and the maximum observed dispersal distance was $600 \mathrm{~m}$ (Table 3; Fig. 3). Females dispersed on average more than twice as far as males (Table 3), but the number of female movements was too few to allow for a significance test. The observed average female flight distance and maximum flight distances are longer than in previous studies of this species (Table 4).

Among the 156 populations that were included in the connectivity analysis, 28 were found to be of importance from a stepping-stone perspective $(\Delta \mathrm{PC}$ connector $>0$; Table S2). Figure S4 (in Electronic Supplementary Material) provides some zoomed-in examples of how the populations were classified according to their position within the network. Figure 4 shows an example of a metapopulation of considerable extent (near Flon, Härjedalen), where the importance of local populations depend on whether there are any alternative stepping stones between the populations that they are connecting

\section{Discussion}

Our study aimed to shed light on the habitat requirements and dispersal ability of Fennoscandian L. helle and test if its local distribution could be predicted from remotely-sensed environmental variables. We could confirm that a warm micro-climate is an important aspect of the habitat quality

models. They had the same directions and similar strengths as the parameter estimates in the best-performing model, meaning that the same general relationships apply as described for the best-performing model

\begin{tabular}{lcllll}
\hline Independent variables & $\begin{array}{l}\text { Unconditional } \\
\text { estimate }\end{array}$ & $\begin{array}{l}\text { Unconditional vari- } \\
\text { ance }\end{array}$ & \# of models found & Importance & +/- (alpha $=0.05)$ \\
\hline (Intercept) & -0.051 & 0.010 & 64 & 1.000 & 0.200 \\
Solar radiation & 0.715 & 0.019 & 32 & 1.000 & 0.269 \\
Slope & -0.296 & 0.013 & 32 & 0.966 & 0.222 \\
Topographic position index & -0.216 & 0.015 & 32 & 0.867 & 0.244 \\
Vegetation height & -0.209 & 0.019 & 32 & 0.821 & 0.272 \\
Northness & -0.010 & 0.001 & 32 & 0.278 & 0.071 \\
Eastness & 0.003 & 0.001 & 32 & 0.265 & 0.057 \\
\hline
\end{tabular}


Fig. 3 The frequency distribution of distances between first capture and last recapture

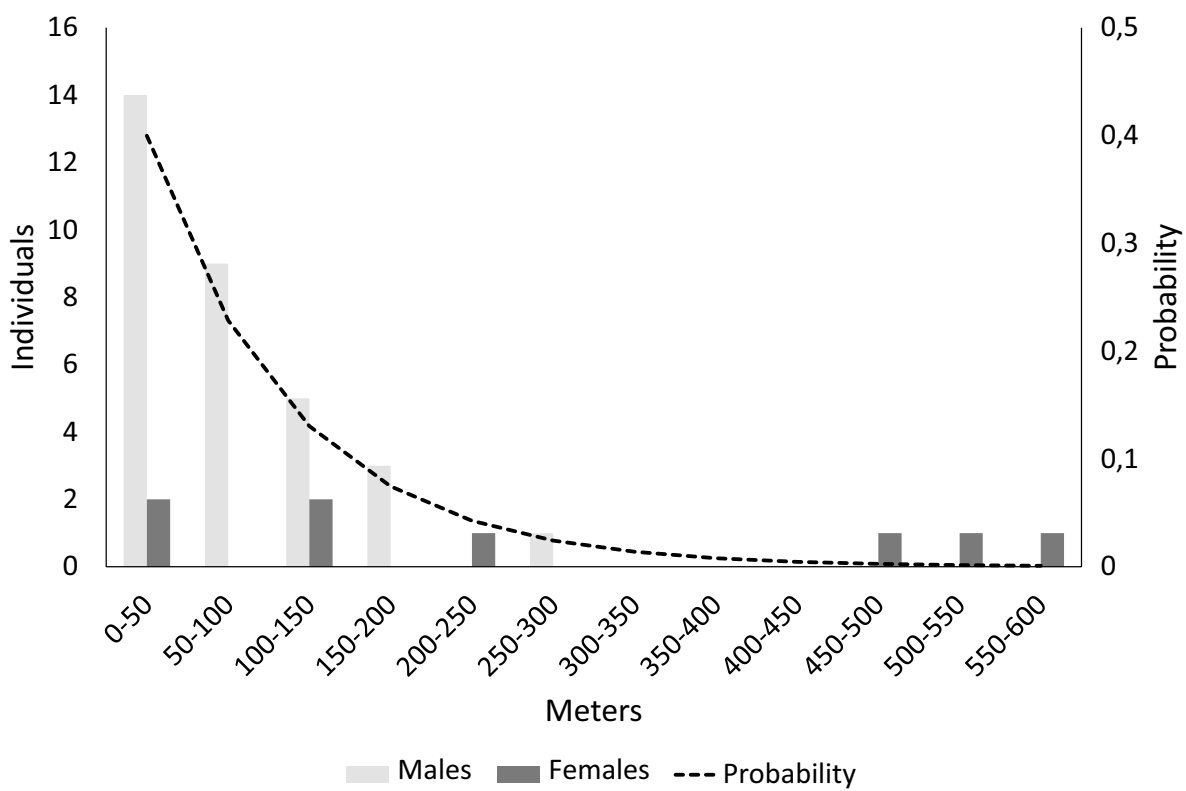

Table 3 Distances (m) between first and last capture

\begin{tabular}{lccllr}
\hline & Mean $( \pm$ SE $)$ & Median & Minimum & Maximum & N \\
\hline Female & $257( \pm 83)$ & 172 & 5 & 600 & 8 \\
Male & $78( \pm 12)$ & 78 & 1 & 298 & 32 \\
All & $114( \pm 22)$ & 82 & 1 & 600 & 40 \\
\hline
\end{tabular}

of this butterfly, as has previously been reported from central Europe. We recorded movement distances than in previous studies of this species, but nevertheless our results confirm that $L$. helle is a relatively sedentary species.

Since a large part of the L. helle occurrences were in power-line corridors, the management of these which aims at maintaining a low, early-successional vegetation through clearing trees and shrubs every 8 years, is apparently favourable for this species. However, our results indicate that $L$. helle would benefit from lower vegetation, which could be achieved by regular mowing and clearing of unwanted vegetation (Svensson et al. 2017). Such management would benefit not only $L$. helle but also a large number of other butterfly species (Berg et al. 2013).

In our study area, L. helle appears to prefer sun-exposed habitat surrounded by low vegetation and avoid habitat that is shaded by surrounding forest during a large part of the day. Also previous studies have suggested that a warm microclimate is a key factor for L. helle survival in Fennoscandia, due to the short season at high latitudes (Ryrholm 2014). Both the larval development (Meyer and Helminger 1994) and adult activity (Lindeborg 2014) are higher in a warm microclimate. However, even though $L$. helle is favoured by sunny conditions, it apparently also need shelter from the wind (Sawchik et al. 2003), so too open conditions might be negative (Fischer et al. 1999; Bauerfeind et al., 2009). We observed a negative relationship between vegetation structure (TPI) and L. helle occurrence, indicating a preference for open homogeneous areas. This is, however, probably an artefact by the fact that TPI values are inflated by the surrounding tall forest along roads, where L. helle was mostly absent. Hence, ongoing restoration of rich fens, where small

Table 4 Flight distances from five mobility studies on L. helle

\begin{tabular}{lllllll}
\hline Location of study & References & $\begin{array}{l}\text { Mean distance } \\
\text { females (m) }\end{array}$ & $\begin{array}{l}\text { Mean distance } \\
\text { males (m) }\end{array}$ & $\begin{array}{l}\text { Mean distance } \\
\text { overall (m) }\end{array}$ & $\begin{array}{l}\text { Maximum flight } \\
\text { distance (m) }\end{array}$ & $\begin{array}{l}\text { Size of study area (ha) } \\
\text { Germany }\end{array}$ \\
Mongolia & Fischer et al. (1999) & 61 & 37 & - & 560 & Unspecified \\
Romania & Gantigmaa et al. (2008) & 107 & 44 & - & 386 & 10 \\
Belgium & Craioveanu et al. (2014) & 111 & 135 & - & 590 & 64 \\
Sweden & Turlure et al. (2014) & - & - & $108^{*}$ & 522 & 14 \\
\hline
\end{tabular}

*This study averaged the flight distances only among the individuals that emigrated or travelled between two habitat patches 
Fig. 4 An example of connected populations in Flon, Härjedalen, Sweden. A higher $\triangle \mathrm{PC}$ value (dPC in the figure) indicate populations that are important for landscape connectivity, and i.e. act as "stepping stones"

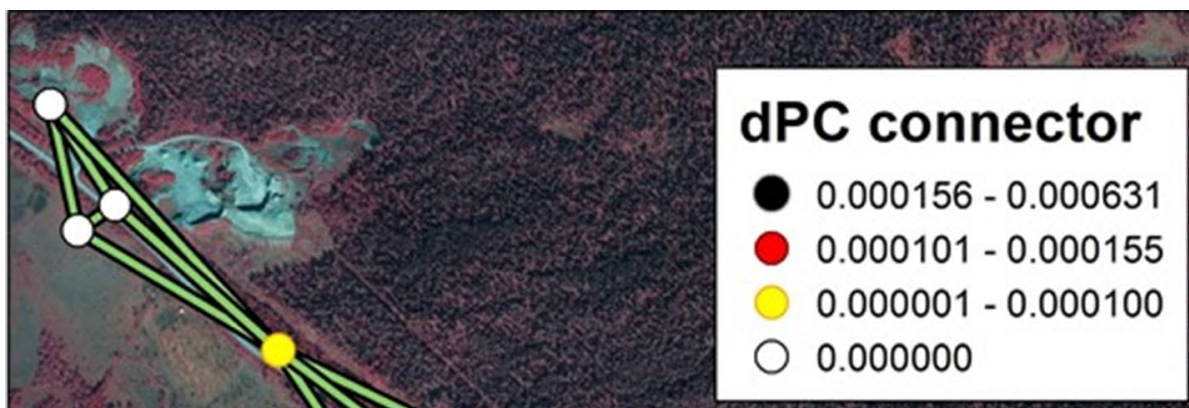

dPC connector

$0.000156-0.000631$

$0.000101-0.000155$

0.000000

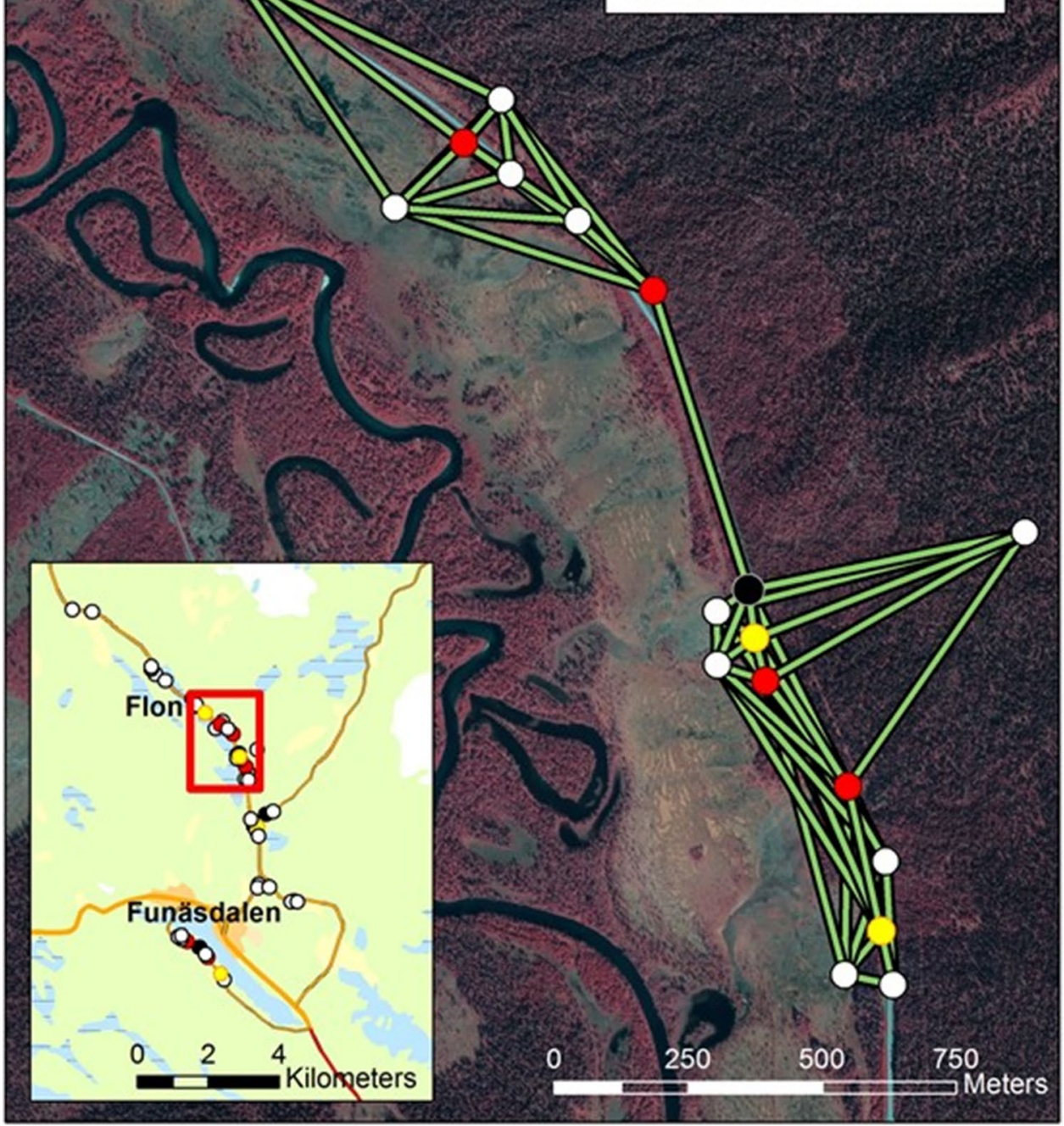

Geodetic reference system: SWEREF 99

Modified from Översiktskartan vektor (2015) from Lantmäteriet and observations from Artportalen (2002-2016)

Background: Orthophoto IR (2017), Lantmäteriet

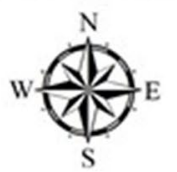

trees and shrubs are removed, might actually have a negative impact on L. helle.

The preference for areas with a warm microclimate is further supported by the relatively weak but negative effect of tall vegetation on $L$. helle occurrence, indicated both by the LiDAR-derived measure of vegetation height, and the measurements in the field. A low vegetation generally results in a warmer micro-climate near the ground level (Eilers et al.
2013), where a certain temperature is necessary for larval development (Bonebrake et al. 2010). This is in contrast with some previous studies. Both Nabielec and Nowicki (2015) and Skórka et al. (2007) found a positive relationship between vegetation height and $L$. helle densities. This difference might be due to climatic factors, such that Fennoscandian populations have a stronger dependence on a warm micro-climate compared to populations in the warmer 
climate in central Europe (Thomas 1993), but could also reflect differences in habitat preferences of the host plants used by L. helle in northern (B. vivipara) and (Bistorta major $[=$ Polygonum bistorta $]$ ) central Europe.

As Fennoscandian L. helle is monophagous on B. vivipara during its larval stage (Ryrholm 2014), the occurrence of this plant is a prerequisite for the occurrence of the butterfly, and host plant density is often an important aspect of butterfly habitat quality (e.g. Fourcade et al. 2017). We found a positive, but relatively weak, relationship between $B$. vivipara density and $L$. helle density. This strongly suggests that that the abundance of the butterfly is primarily limited by other aspects of habitat quality, such as microclimate, or that it is only able to use a small fraction of the available $B$. vivipara plants, i.e. when it grows under certain conditions (Thomas et al. 2001), or a combination of these. Hence, increasing the abundance of the host plant alone is not enough to restore L. helle habitat.

The resource selection function used to predict the occurrence of $L$. helle from remotely-sensed data performed relatively poorly. The AUROC was 0.685 , which means that the distribution of the species can only be predicted by the included variables to a limited extent (Fielding and Bell 1997; cf. Settele et al. 2008). The performance of the RSF was probably influenced by the relatively low number of butterfly observations $(\mathrm{N}=229)$, but perhaps also by a low variability of habitat quality within the study area. It should be noted that only areas that were regarded as "potential habitat" were included in the model. Hence, any large-scale application of this RSF requires a first step where potential habitat is identified e.g. from aerial photographs. Future studies should assess whether the RSF can identify suitable habitat at a regional scale.

Our results, although based on a low number of recaptured individuals, confirmed that $L$. helle is a relatively sedentary species. The higher capture rate for males than for females probably reflects that $L$. helle males, as in other closely related species are territorial (Fischer and Fiedler 2001), and hence more visible. Nevertheless, L. helle females moved on average longer distances, which is important in a metapopulation perspective where dispersing females have the possibility to (re-)establish new populations. Despite the limited sample size, we observed longer dispersal distances than in previous studies of this species. Mark-recapture studies always underestimate total mobility (Shreeve 1992), but to varying degrees, and the risk of underestimating longdistance movement is naturally higher if the size of the study area is small (Schneider 2003). Our study area was larger than in previous studies (see Table 4), and hence this could explain the longer observed dispersal distances. It is also possible that the observed dispersal distances were influenced by the degree of habitat fragmentation (Schtickzelle et al. 2006). It is difficult to directly compare the level of habitat fragmentation between the studies in Table 4, but the area in Germany studied by Fischer at al. (1999) was described as having a high degree of fragmentation, with grassland patches in a spruce forest matrix, while the study areas in Mongolia (Gantigmaa et al. 2008), Romania (Craioveanu et al. 2014) were more continuous. Our study area was characterized by narrow but elongated habitat patches, which might contribute to a relatively high population connectivity, and could explain the longer movement in our study especially compared to Fischer at al. (1999).

We applied our estimates of dispersal in a connectivity analysis with the aim was of identifying populations that are important for regional connectivity. However, it should be kept in mind that the analysis is based solely on straight line distances, and no consideration has been taken to the presence of barriers, corridors or other landscape features that could potentially affect movements (Caplat et al. 2016), and hence represent an oversimplification. Also, basing the connectivity analysis on mark-recapture data, which tends to under-estimate dispersal, leads to a likely underestimation of true connectivity (Shreeve 1992). This is probably accentuated by the fact that our dispersal etimates were based on a low sample size. Recent intensive and large-scale studies on butterflies have revealed that long-distance dispersal exists in species that are regarded as sedentary (Zimmermann et al. 2011). Observed colonisation events and genetic analyses suggest that adults of $L$. helle can actually move larger distances than estimated in mark-recapture studies (Finger et al. 2009; Turlure et al. 2014). However simplified and with uncertain estimates of dispersal distances, the connectivity analysis can provide a much-needed indication of which populations that are most important from a connectivity perspective.

\section{Conclusions and implications for conservation}

Although L. helle was found in a few different land use types, our study confirms that this butterfly species is specialized on habitat conditions that are becoming increasingly rare in modern production landscapes. Interestingly, the majority of the current occurrences in our study area, but also elsewhere in Sweden are in man-made habitats such as road verges and power-line corridors. This highlights the importance of managing such habitats for biodiversity conservation purposes (Gardiner et al. 2018), and including authorities and companies responsible for these infrastructures in landscape-scale conservation plans.

The low dispersal ability of $L$. helle makes it vulnerable to climate change since it has limited capacity to shift its distribution in response to climate change. Hence, future conservation efforts that retain or improve connectivity are 
vital for the long-term viability of the species. Conservation efforts should be directed to the preservation of metapopulations, since large networks of populations have a considerably higher viability and potential of adapting to new environmental conditions. Our connectivity analysis identified several stepping stone populations which are important for the long-term persistence of $L$. helle metapopulations, and hence are particularly important from a conservation perspective. We suggest that this could be a useful approach for identifying and prioritizing sites where habitat could be restored or created to ensure the long-term persistence of $L$. helle, and other rare species with fragmented distributions.

Acknowledgements Open access funding provided by Swedish University of Agricultural Sciences. This paper was based on the MSc thesis by HM (Modin 2018). We thank the County Administrative Board in Jämtland, especially Bodil Carlsson and Magnus Magnusson for being part of this collaboration and for providing us with the necessary equipment and information during the field study. Gesa von Hirschheydt provided valuable feedback on a previous version of the text. We received financial support from the Entomological Society of Uppland (to HM) and from the Swedish Research Council Formas (Contract 942-2015-988; to EÖ).

Author contributions Both authors contributed to the study conception and design. Field data collection and analyses were performed by HM under supervision of EÖ. The first draft of the manuscript was written by HM, and the final version of the manuscript was prepared by EÖ. Both authors read and approved the final manuscript.

\section{Compliance with Ethical Standards}

Conflict of interest Permission to capture and mark butterflies in the nature reserve Tysjöarna was granted by the County Adminstrative Board in Jämtland. No other legal permits were required to carry out the study. The authors declare that they have no conflict of interest.

Open Access This article is licensed under a Creative Commons Attribution 4.0 International License, which permits use, sharing, adaptation, distribution and reproduction in any medium or format, as long as you give appropriate credit to the original author(s) and the source, provide a link to the Creative Commons licence, and indicate if changes were made. The images or other third party material in this article are included in the article's Creative Commons licence, unless indicated otherwise in a credit line to the material. If material is not included in the article's Creative Commons licence and your intended use is not permitted by statutory regulation or exceeds the permitted use, you will need to obtain permission directly from the copyright holder. To view a copy of this licence, visit http://creativecommons.org/licenses/by/4.0/.

\section{References}

Artdatabanken (2015) Rödlistade arter i Sverige 2015. ArtDatabanken, Uppsala

Berg A, Ahrné K, Öckinger E, Svensson R, Wissman J (2013) Butterflies in semi-natural pastures and power-line corridors-effects of flower richness, management, and structural vegetation characteristics. Insect Conserv Divers 6:639-657. https://doi.org/10.1111/ icad.12019
Bonebrake TC, Boggs CL, McNally JM, Ranganathan J, Ehrlich PR (2010) Oviposition behavior and offspring performance in herbivorous insects: consequences of climatic and habitat heterogeneity. Oikos 119:927-934

Boyce MS, Vernier PR, Nielsen SE, Schmiegelow FKA (2002) Evaluating resource selection functions. Ecol Model 157:281-300. https ://doi.org/10.1016/S0304-3800(02)00200-4

Calcagno V, de Mazancourt C (2010) glmulti: An R package for easy automated model selection with (Generalized) Linear Models. J Stat Softw 34(12):1-29. https://doi.org/10.18637/jss.v034.i12

Caplat $\mathrm{P}$ et al (2016) Looking beyond the mountain: dispersal barriers in a changing world. Front Ecol Environ 14:261-268. https://doi. org/10.1002/fee. 1280

Craioveanu C, Sitar C, Rakosy L (2014) Mobility, behaviour and phenology of the Violet Copper Lycaena helle in North-Western Romania. In: Habel JC, Meyer M, Schmitt T (eds) Jewels in the Mist-a\&nbsp;synopsis on the highly endangered butterfly species the Violet Copper, Lycaena helle. Pensoft Publishers, Sofia

Dennis RLH, Shreeve TG, Van Dyck H (2003) Towards a functional resource-based concept for habitat: a butterfly biology viewpoint. Oikos 102:417-426

Eilers S, Pettersson LB, ÖCkinger E (2013) Micro-climate determines oviposition site selection and abundance in the butterfly Pyrgus armoricanus at its northern range margin. Ecol Entomol 38:183192. https://doi.org/10.1111/een.12008

Eliasson CU, Ryrholm N, Holmer M, Jilg K, Gärdenfors U (2005) Nationalnycklen till Sveriges flora och fauna. Fjärilar: Dagfjärilar. Hesperiidae-Nymphalidae. ArtDatabanken, SLU, Uppsala

Eliasson CU (2012) Fact sheet: Lycaena helle Violett guldvinge. https ://artfakta.artdatabanken.se/taxon/101248. Accessed 18 May 2017

ESRI (2017) ArcGIS Desktop: Release 10. Environmental Systems Research Institute, Redlands

Fielding AH, Bell JF (1997) A review of methods for the assessment of prediction errors in conservation presence/absence models. Environ Conserv 24:38-49. https://doi.org/10.1017/S037689299 7000088

Finger A, Schmitt T, Emmanuel Zachos F, Meyer M, Assmann T, Christian Habel J (2009) The genetic status of the violet copper Lycaena helle-a relict of the cold past in times of global warming. Ecography 32:382-390. https://doi.org/10.111 1/j.1600-0587.2008.05766.x

Fischer K, Beinlich B, Plachter H (1999) Population structure, mobility and habitat preferences of the violet copper Lycaena helle (Lepidoptera: Lycaenidae) in Western Germany: implications for conservation. J Insect Conserv 3:43-52. https://doi. org/10.1023/a:1009630506216

Fischer K, Fiedler K (2001) Resource-based territoriality in the butterfly Lycaena hippothoe and environmentally induced behavioural shifts. Anim Behav 61:723-732. https://doi.org/10.1006/ anbe. 2000.1662

Fleishman E, Ray C, Sjögren-Gulve P, Boggs CL, Murphy DD (2002) Assessing the roles of patch quality, area, and isolation in predicting metapopulation dynamics. Conserv Biol 16:706-716

Fourcade Y, Öckinger E (2017) Host plant density and patch isolation drive occupancy and abundance at a butterfly's northern range margin. Ecol Evol 7:331-345. https://doi.org/10.1002/ece3.2597

Fourcade Y, Ranius T, Öckinger E (2017) Temperature drives abundance fluctuations, but spatial dynamics is constrained by landscape configuration: implications for climate-driven range shift in a butterfly. J Anim Ecol 86:1339-1351. https://doi. org/10.1111/1365-2656.12740

Gantigmaa C, Muehlenberg M, Altantsetseg M (2008) Habitat occupancy and mobility of the violet copper (Lycaena helle) in west Khentii, northern Mongolia. Mongolian J Biol Sci 6:39-44 
Gardiner MM, Riley CB, Bommarco R, Öckinger E (2018) Rightsof-way: a potential conservation resource. Front Ecol Environ 16:149-158. https://doi.org/10.1002/fee.1778

Hanski I (1998) Metapopulation dynamics. Nature 396:41-49

Hanski I (1999) Metapopulation ecology. Oxford series in ecology and evolution. Oxford University Press, Oxford

Heller NE, Zavaleta ES (2009) Biodiversity management in the face of climate change: a review of 22 years of recommendations. Biol Conserv 142:14-32

Jenness J (2006) Topographic position index (TPI) v. 1.2. http://www. jennessent.com/arcview/tpi.htm. Jenness Enterprise

Leidenberger S, Käck M, Karlsson B, Kindvall O (2016) The analysis portal and the Swedish lifewatch e-infrastructure for biodiversity research. Biodivers Data J 4:e7644. https://doi.org/10.3897/ BDJ.4.e7644

Lindeborg M (2014) Åtgärdsprogram för violett guldvinge, 2014-2018. Naturvårdsverket, Stockholm

Manly BF, McDonald L, Thomas DL, McDonald TL, Erickson WP (2007) Resource selection by animals: statistical design and analysis for field studies. Springer, Dordrecht

Meyer M, Helminger T (1994) Studies of a population of Lycaena helle arduinnae Meyer, 1980 in the northwestern Oesling region (Lepidoptera, Lycaenidae). Bulletin de la Societe des Naturalistes Luxembourgeois 115:315-326

Modin H (2018) Mobility, habitat preferences and connectivity of Lycaena helle in northwest Sweden - Implications for conservation. MSc thesis in Biology. Department of Ecology, Swedish University of Agricultural Sciences, Uppsala. https://stud.epsil on.slu.se/13488/

Morris LR, Proffitt KM, Blackburn JK (2016) Mapping resource selection functions in wildlife studies: Concerns and recommendations. Appl Geogr 76:173-183. https://doi.org/10.1016/j.apgeo g.2016.09.025

Mutanen M, Välimäki P (2014) Habitat requirements, threats and trends in the distribution of the Violet Copper Lycaena helle at its northern distribution margin in Finland. In: Habel JC, Meyer M, Schmitt T (eds) Jewels in the mist-a\&nbsp;synopsis on the endangered Violet Copper butterfly Lycaena helle. Pensoft Publishers, Sofia

Nabielec J, Nowicki P (2015) Drivers of local densities of endangered Lycaena helle butterflies in a fragmented landscape. Popul Ecol 57:649-656. https://doi.org/10.1007/s10144-015-0507-0

Nordkvist K, Olsson H (2013) Laserskanning och digital fotogrammetri i skogsbruket. Institutionen för skoglig resurshushållning, Sveriges Lantbruksuniversitet., Ume\&\#229

Öckinger E et al (2010) Life-history traits predict species responses to habitat area and isolation: a cross-continental synthesis. Ecol Lett 13:969-979. https://doi.org/10.1111/j.1461-0248.2010.01487.x

Pimm SL et al (2014) The biodiversity of species and their rates of extinction, distribution, and protection. Science 344:1246752. https://doi.org/10.1126/science.1246752

R Development Core Team (2017) R: A language and environment for statistical computing. https://www.R-project.org/

Ryrholm N (2014) The Violet Copper Lycaena helle at its northern distribution range. In: Habel JC, Meyer M, Schmitt T (eds) Jewels in the mist-a\&nbsp;synopsis on the endangered Violet Copper butterfly Lycaena helle. Pensoft Publishers, Sofia

Saunders DA, Hobbs RJ, Margules CR (1991) Biological consequences of ecosystem fragmentation: a review. Conserv Biol 5:18-32

Saura S, Pascual-Hortal L (2007) A new habitat availability index to integrate connectivity in landscape conservation planning: comparison with existing indices and application to a case study. Landsc Urban Plan 83:91-103. https://doi.org/10.1016/j.landu rbplan.2007.03.005
Saura S, Rubio L (2010) A common currency for the different ways in which patches and links can contribute to habitat availability and connectivity in the landscape. Ecography 33:523-537. https://doi. org/10.1111/j.1600-0587.2009.05760.x

Saura S, Torné J (2012) Conefor Sensinode 2.6: a software package for quantifying the importance of habitat patches for landscape connectivity. Environ Model Softw 24:135-139

Saura S, Bodin Ö, Fortin M-J (2014) Stepping stones are crucial for species' long-distance dispersal and range expansion through habitat networks. J Appl Ecol 51:171-182. https://doi. org/10.1111/1365-2664.12179

Sawchik J, Dufrêne M, Lebrun P (2003) Estimation of habitat quality based on plant community, and effects of isolation in a network of butterfly habitat patches. Acta Oecol 24:25-33

Schmidt M, Lipson H (2014) Eureqa version 0.98 beta [Software]. https ://www.nutonian.com/

Schneider C (2003) The influence of spatial scale on quantifying insect dispersal: an analysis of butterfly data. Ecol Entomol 28:252-256

Schtickzelle N, Mennechez G, Baguette M (2006) Dispersal depression with habitat fragmentation in the bog fritillary butterfly. Ecology 87:1057-1065

Settele J et al (2008) Climatic risk atlas of European butterflies. BioRisk $1: 1-710$

Shreeve TG (1992) Monitoring butterfly movements. In: Dennis RLH (ed) The ecology of butterflies in Britain. Oxford University Press., Oxford, pp 120-138

Skórka P, Settele J, Woyciechowski M (2007) Effects of management cessation on grassland butterflies in southern Poland. Agric Ecosyst Environ 121:319-324

Svensson R, Berg Å, Hamring L, Rätz C, Zhmihorski M (2017) Slåtterhävd i kratledningsgator - en 13-årig studie. Svensk Botanisk Tidskrift 111:16-28

Thomas JA (1993) Holocene climate changes and warm man-made refugia may explain why a sixt of British butterflies possess unnatural early-successional habitats. Ecography 16:278-284

Thomas JA et al (2001) The quality and isolation of habitat patches both determine where butterflies persist in fragmented landscapes. Proc R Soc Lond Ser B 268:1791-1796

Thomas JA (2005) Monitoring change in the abundance and distribution of insects using butterflies and other indicator groups. Philos Trans R Soc Lond B 360:339-357

Turlure C, Van Dyck H, Goffart P, Schtickzelle N (2014) Resource based habitat use in Lycaena helle: Significance of a functional, ecological niche-oriented approach. In: Habel JC, Meyer M, Schmitt T (eds) Jewels in the Mist - A synopsis on the highly endangered butterfly species the Violet Copper, Lycaena helle. Pensoft Publishers, Sofia

van Swaay C et al (2010) European Red List of Butterfies. Publications Office of the European Union, Luxembourg

Zimmermann K, Fric Z, Jiskra P, Kopeckova M, Vlasanek P, Zapletal M, Konvica M (2011) Mark-recapture on large spatial scale reveals long distance dispersal in the Marsh Fritillary, Euphydryas aurinia. Ecol Entomol 36:499-510. https://doi.org/10.111 1/j.1365-2311.2011.01293.x

Zweig MH, Campbell G (1993) Receiver-operating characteristic (ROC) plots: a fundamental evaluation tool in clinical medicine. Clin Chem 39(4):561-577

Publisher's Note Springer Nature remains neutral with regard to jurisdictional claims in published maps and institutional affiliations. 